\title{
Embriogênese somática em híbridos de Pennisetum sp. e avaliação de estabilidade genômica por citometria
}

\author{
José Marcello Salabert de Campos(1), Clara de Azevedo Calderano ${ }^{(2)}$, Antônio Vander Pereira(1), \\ Lisete Chamma Davide ${ }^{(3)}$, Lyderson Facio Viccini( ${ }^{(2)}$ e Marcelo de Oliveira Santos ${ }^{(2)}$
}

\begin{abstract}
(1)Embrapa Gado de Leite, Rua Eugênio do Nascimento, no 610, Bairro Dom Bosco, CEP 36038-330 Juiz de Fora, MG. E-mail: jmscampos@yahoo.com.br, avanderp@cnpgl.embrapa.br (2)Universidade Federal de Juiz de Fora, Instituto de Ciências Biológicas, Departamento de Biologia, CEP 36036-900 Juiz de Fora, MG. E-mail: clarinhaz@hotmail.com, lyderson.viccini@ufjf.edu.br, marcelo.santos@ufff.edu.br (3)Universidade Federal de Lavras, Departamento de Biologia, CEP 37200-000 Lavras, MG. E-mail: Icdavide@ufla.br
\end{abstract}

Resumo - Os objetivos deste trabalho foram estabelecer um protocolo eficiente de embriogênese somática, em híbridos triploides entre capim-elefante (Pennisetum purpureum Schumach.) e milheto (P. glaucum (L.) R. Br.), e avaliar por citometria de fluxo a estabilidade genômica das plantas obtidas in vitro. A embriogênese somática e a regeneração das plantas foram estabelecidas a partir de embriões zigóticos maduros de híbridos entre capim-elefante e milheto. Foram testados quatro tratamentos com 2,4-ácido diclorofenoxiacético (2,4-D), nas concentrações $0,1,2$ e $3 \mathrm{mg} \mathrm{L}^{-1}$, para indução de calos embriogênicos, e dois tratamentos com inositol a 1 e $2 \mathrm{~g} \mathrm{~L}^{-1}$, para regeneração das plantas. Os tratamentos foram dispostos em delineamento inteiramente ao acaso. A combinação ótima de hormônios foi de $2 \mathrm{mg} \mathrm{L}^{-1}$ de 2,4-D, para indução de calos embriogênicos, e de $1 \mathrm{~g} \mathrm{~L}^{-1}$ de inositol, para conversão de embriões e regeneração de plantas. A análise de quantidade de DNA, por citometria de fluxo das plantas regeneradas, indicou a não ocorrência de alterações em ploidia durante a embriogênese somática e a regeneração das plantas. A quantidade de DNA nuclear e a ploidia das plantas regeneradas foram estáveis e homogêneas em comparação às das plantas controle. Não ocorreu instabilidade cariotípica no sistema de regeneração usado para híbridos de Pennisetum.

Termos para indexação: Pennisetum glaucum, Pennisetum purpureum, cultura de tecidos.

\section{Somatic embryogenesis in hybrids of Pennisetum sp. and genomic stability evaluation by cytometry}

\begin{abstract}
The objectives of this study were to establish an efficient protocol for somatic embryogenesis in triploid hybrids between napiergrass (Pennisetum purpureum Schumach.) and pearl millet (P. glaucum (L.) R. $\mathrm{Br}$.), and to assess the genomic stability by flow cytometry of the plants obtained in vitro. Somatic embryogenesis and plant regeneration were successfully established from mature zygotic embryos of napiergrass and pearl millet hybrids. Four treatments with 2,4-dichlorophenoxyacetic acid (2,4-D) at 0, 1, 2 e $3 \mathrm{mg} \mathrm{L}^{-1}$ were tested for

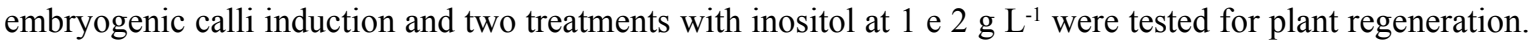
The treatments were arranged in a completely randomized design. The optimum hormone combinations were $2 \mathrm{mg} \mathrm{L}^{-1}$ of 2,4-D for embryogenic callus induction, and $1 \mathrm{~g} \mathrm{~L}^{-1}$ of inositol for embryos conversion and plant regeneration. The analysis of DNA content by flow cytometry of the regenerated plantlets indicated that no ploidy changes had been induced during somatic embryogenesis and plant regeneration. The nuclear DNA content and ploidy levels of the regenerated plants were stable and homogeneous in comparison to those of the control plants. There was no occurrence of karyological instability in the regeneration system utilized for Pennisetum hybrid.
\end{abstract}

Index terms: Pennisetum glaucum, Pennisetum purpureum, tissue culture.

\section{Introdução}

Um dos mais importantes gêneros da família Poaceae é o Pennisetum (Martel et al., 2004). O capim-elefante (P. purpureum Schumach.) é uma espécie perene, alógama e tetraploide $(2 \mathrm{n}=4 \mathrm{x}=28)$ segundo Martel et al. (1996). Seu potencial produtivo, associado à boa qualidade, palatabilidade, vigor e perenidade, tem estimulado não só o seu cultivo como também o seu melhoramento genético para o desenvolvimento de cultivares melhoradas (Sobrinho et al., 2005). O milheto [P. glaucum (L.) R.Br] é uma espécie anual, alógama e diploide $(2 \mathrm{n}=2 \mathrm{x}=14)$, de acordo com Martel et al. (1996). O milheto apresenta boa resistência à seca e a doenças, é tolerante a baixos níveis de fertilidade 
do solo, tem boa produção de sementes não deiscentes e produz elevado rendimento de matéria seca (Pereira et al., 2001).

A proximidade genética entre o capim-elefante e o milheto possibilita a obtenção de híbridos entre essas duas espécies com relativa facilidade e, em razão disso, essa estratégia tem sido recomendada para o melhoramento da qualidade forrageira (Hanna, 1999). O cruzamento entre essas duas espécies resulta em um híbrido interespecífico triploide $(2 n=3 x=21$ cromossomos) e estéril, que se assemelha morfologicamente ao capim-elefante e apresenta algumas características intermediárias entre as duas espécies parentais (Hanna, 1999). Esse cruzamento busca reunir no híbrido características desejáveis do milheto, tais como tolerância à seca e resistência a doenças, com as boas características do capim-elefante, como potencial produtivo, palatabilidade, vigor e perenidade (Schank et al., 1993).

A necessidade de propagação assexuada dos híbridos triploides, em razão de sua esterilidade, é uma das limitações do emprego desses materiais nos programas de melhoramento. Contudo, as técnicas de propagação clonal in vitro representam uma alternativa para multiplicar, eficientemente, genótipos elite de híbridos triploides entre capim-elefante e milheto. Entre as técnicas de propagação in vitro, a embriogênese somática é frequentemente relatada como uma das principais metodologias de propagação de genótipos elite, uma vez que os meristemas radiculares e apicais estão presentes simultaneamente nos embriões somáticos (Kim, 2000).

Alguns estudos relatam protocolos de embriogênese somática, em espécies do gênero Pennisetum, a partir de embriões maduros e explantes foliares (Arockiasamy et al., 2006), embriões imaturos (Lambé et al., 1998) e inflorescências imaturas (Pius et al., 1993), bem como a partir de brotos apicais (Botti \& Vasil, 1983). Entretanto, são raros os relatos sobre o uso de embriogênese somática para híbridos de $P$. purpureum e P. glaucum.

Embora a embriogênese somática seja apontada como uma metodologia segura de propagação in vitro, a possibilidade de variação somaclonal tem sido demonstrada (Jain, 2001). As variações cromossômicas numéricas, tais como aneuploidias e poliploidias, são as alterações mais comuns e geralmente estão associadas à idade da cultura e a estresse por reguladores de crescimento ou a ambos (Cassels \& Curry, 2001). Assim, a disponibilidade de um protocolo de embriogênese somática, que minimize a presença da variação somaclonal, é fundamental para se aumentar a eficiência da clonagem assexuada de genótipos elite de híbridos entre capim-elefanteemilheto.Paralelamente, édesejável a avaliação periódica dessa instabilidade genômica, por meio de um método rápido e ao mesmo tempo preciso. A citometria de fluxo tem sido extensivamente utilizada com esse propósito, em vários estudos, tais como os das espécies Juniperus phoeniceae (Loureiro et al., 2007), Scutellaria baicalensis (Alan et al., 2007), Eucalyptus globulus (Pinto et al., 2004) e Quercus robur (Endemann et al., 2001).

Os objetivos do trabalho foram estabelecer um protocolo eficiente de embriogênese somática, em híbridos triploides entre capim-elefante e milheto, e avaliar a estabilidade genômica das plantas obtidas in vitro, por citometria de fluxo.

\section{Material e Métodos}

Sementes triploides oriundas do cruzamento entre os parentais F91-2-5 (capim-elefante) e M-31 (milheto) foram utilizadas nos experimentos. Esse cruzamento constitui um dos híbridos que fazem parte do programa de melhoramento de forragem da Embrapa Gado de Leite, em Juiz de Fora, MG. As sementes foram esterilizadas por $1 \mathrm{~min}$ em etanol absoluto, $20 \mathrm{~min}$ em hipoclorito de sódio $2 \%$ e, posteriormente, foram lavadas quatro vezes em água destilada autoclavada. Embriões maduros foram extraídos a partir das sementes e utilizados para indução de embriogênese somática em quatro tratamentos de 2,4-D, nas concentrações $0,1,2$ e $3 \mathrm{mg} \mathrm{L}^{-1}$, em meio MS (Murashige \& Skoog, 1962) (Phytotechlab) com $30 \mathrm{~g} \mathrm{~L}^{-1}$ de sacarose e $6 \mathrm{~g} \mathrm{~L}^{-1}$ de ágar. Os embriões foram mantidos no escuro, a $25^{\circ} \mathrm{C}$, por quatro semanas, para indução dos calos embriogênicos. Os tratamentos foram dispostos em delineamento inteiramente ao acaso, com três repetições. Cada repetição foi obtida da análise de três placas de Petri, cada uma com dez embriões. A análise estatística dos percentuais de calos e de calos embriogênicos, produzidos a partir de cada tratamento, foi realizada por análise de variância e análise de regressão, a 5\% de probabilidade.

Os calos embriogênicos produzidos nos tratamentos de $1 \mathrm{mg} \mathrm{L}^{-1}$ de 2,4-D, depois de quatro semanas de 
indução, foram repicados em meio MS com 1, 2 e $3 \mathrm{mg} \mathrm{L}^{-1}$ de 2,4-D e mantidos por mais quatro semanas para indução de embriogênese secundária. Após esse período, os calos foram transferidos para meio de regeneração MS sem reguladores de crescimento, com 1 ou $2 \mathrm{~g} \mathrm{~L}^{-1}$ de inositol. Posteriormente, os calos que possuíam embriões maduros foram transferidos para meio MS em presença da luz, com o objetivo de induzir a formação de brotos e enraizamento (fase de conversão em plantas).

As plântulas obtidas foram aclimatadas, cobertas com filme de plástico durante 14 dias e, posteriormente, foram transplantadas para vasos com solo e plantmax (1:1) e cultivadas em casa de vegetação. As plantas com 1 mês de idade foram posteriormente analisadas por citometria de fluxo, para se averiguar a estabilidade genômica.

Três plantas triploides, obtidas por germinação de sementes e mantidas em vasos, foram utilizadas como controle. De cada planta, foram avaliadas três amostras de diferentes setores do tecido foliar, e cada uma delas foi considerada como uma repetição (delineamento inteiramente ao acaso com três repetições). A análise estatística foi realizada por comparação das quantidades de DNA entre plantas, por teste de média (Tukey, $\mathrm{p}<0,05$ ). De cada amostra, 20 a $30 \mathrm{mg}$ de tecido foliar jovem, junto com a mesma massa foliar de Pisum sativum L. (padrão de referência de quantidade de DNA - 9,09 pg) foram triturados em placa de Petri, com $1 \mathrm{~mL}$ do tampão de extração de núcleos LBO1 (Dolezel \& Bartos, 2005). A solução de núcleos foi aspirada através de duas camadas de gaze, para filtragem do tecido triturado e, posteriormente, filtrada em malha de $50 \mu \mathrm{m}$ (Millipore) e coletada em um tubo de poliestireno. A suspensão nuclear foi corada com $25 \mu \mathrm{L}$ de uma solução composta de iodeto de propídeo $\left(1 \mathrm{mg} \mathrm{mL}^{-1}\right)$ e $5 \mu \mathrm{L}$ de RNase. As amostras foram armazenadas em refrigerador, no escuro, e analisadas em até 1 hora após o preparo. Para cada amostra, pelo menos 10 mil núcleos foram analisados quanto à emissão de fluorescência, para quantificação de DNA. Os histogramas foram obtidos no citômetro FacsCalibur (Becton Dickinson) com o programa Cell Quest. As quantidades de DNA (pg) das plantas foram obtidas por meio da equação: quantidade de DNA (pg) $=$ (posição do pico G1 da amostra/posição do pico G1 de P. sativum) x 9,09. A análise estatística dos dados foi realizada pelo programa WinMDI 2.8 (http://www. cyto.purdue.edu/flowcyt/software/Winmdi.htm).

\section{Resultados e Discussão}

Para os percentuais de produção de calos e de calos embriogênicos em função da concentração de 2,4-D ( $0,1,2$ e $\left.3 \mathrm{mg} \mathrm{L}^{-1}\right)$, foram observados modelos quadráticos na análise de regressão, com valores máximos de $75,86 \%$ de calos, na concentração de $2 \mathrm{mg} \mathrm{L}^{-1}$ e $27,34 \%$ de calos embriogênicos, na concentração de $1,8 \mathrm{mg} \mathrm{L}^{-1}$ (Figura 1).

Os calos embriogênicos oriundos do tratamento com $1 \mathrm{mg} \mathrm{L}^{-1}$ foram subcultivados em diferentes concentrações, para induzir a embriogênese secundária. A multiplicação em meio com $1 \mathrm{mg} \mathrm{L}^{-1}$ de 2,4-D foi mantida, enquanto a maioria dos calos subcultivados em meio com 2 ou $3 \mathrm{mg} \mathrm{L}^{-1}$ oxidaram e morreram.

A embriogênese somática é um processo biológico complexo, que é induzido artificialmente por diferentes condições de estresse como, por exemplo, redução do potencial osmótico do meio de cultivo e adição de auxinas. Em geral, o 2,4-D é o agente indutor mais utilizado, pois induz genes responsáveis pela sinalização do processo de embriogênese somática. No híbrido entre $P$. purpureum $\times$ P. americanum, a embriogênese foi induzida com sucesso, em meio suplementado com esse regulador de crescimento (Haydu \& Vasil, 1981).

Quanto à regeneração de brotos, os calos embriogênicos originados do tratamento com $1 \mathrm{mg} \mathrm{L}^{-1}$ de 2,4-D - e mantidos na etapa de conversão, em meio

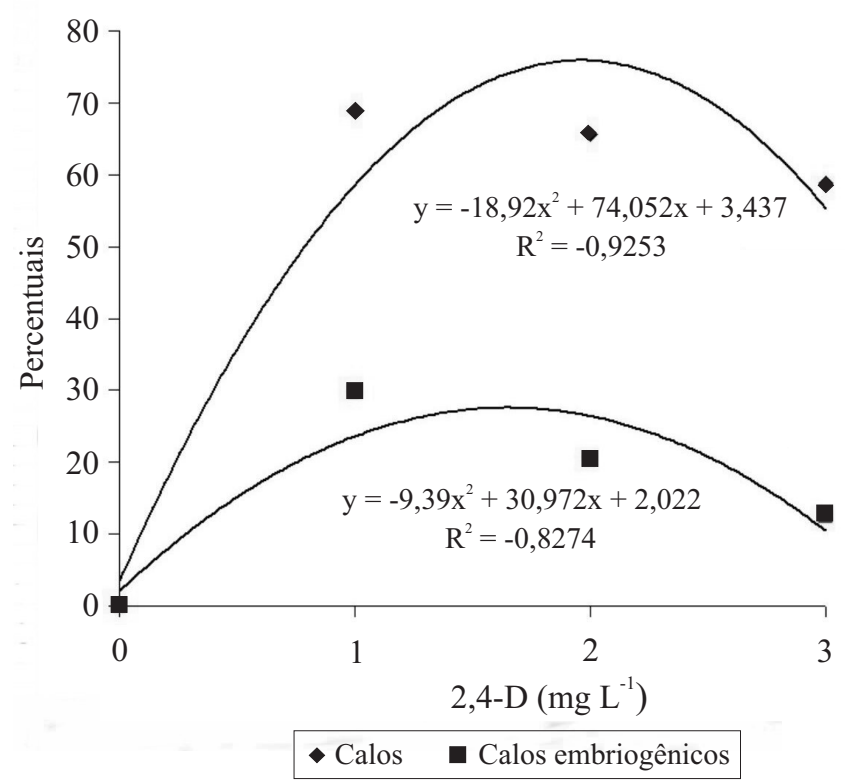

Figura 1. Percentuais de calos e de calos embriogênicos, produzidos a partir de diferentes tratamentos com 2,4-D. 
suplementado com $1 \mathrm{~g} \mathrm{~L}^{-1}$ de inositol - apresentaram os melhores resultados, e foi possível observar $25,31 \%$ dos calos com brotações. A partir deste tratamento, foi possível obter26 plantas adultas que, subsequentemente, foram analisadas por citometria de fluxo. No entanto, os calos tratados com 2 e $3 \mathrm{mg} \mathrm{L}^{-1}$ de 2,4-D resultaram em baixa ou nenhuma conversão, o que demonstra que o tratamento de origem do calo embriogênico pode afetar significativamente a regeneração das plantas.

As etapas de obtenção de calos embriogênicos e plantas, a partir de embriões zigóticos de híbridos $P$. purpurem e $P$. glaucum, estão representadas na Figura 2.
A quantidade de DNA média, para as plantas obtidas por embriogênese somática, foi de $4,51 \pm 0,06 \mathrm{pg}$, com variação de 4,49 a $4,56 \mathrm{pg}$. Os valores de quantidade de DNA individuais das plantas não foram estatisticamente diferentes $(\mathrm{p}>0,05)$ das plantas controle (média de 4,50£0,04 pg). Para todas as plantas analisadas, os percentuais de células em G1 e G2 $(67,89 \pm 5,67$ e 7,78+1,45) e os coeficientes de variação $(2,12 \pm 0,56)$ foram considerados normais, para uma população de células em um ciclo celular ativo, o que permite boas estimativas da quantidade de DNA (Dolezel et al., 2007). Histogramas representativos das quantidades de DNA das plantas analisadas são
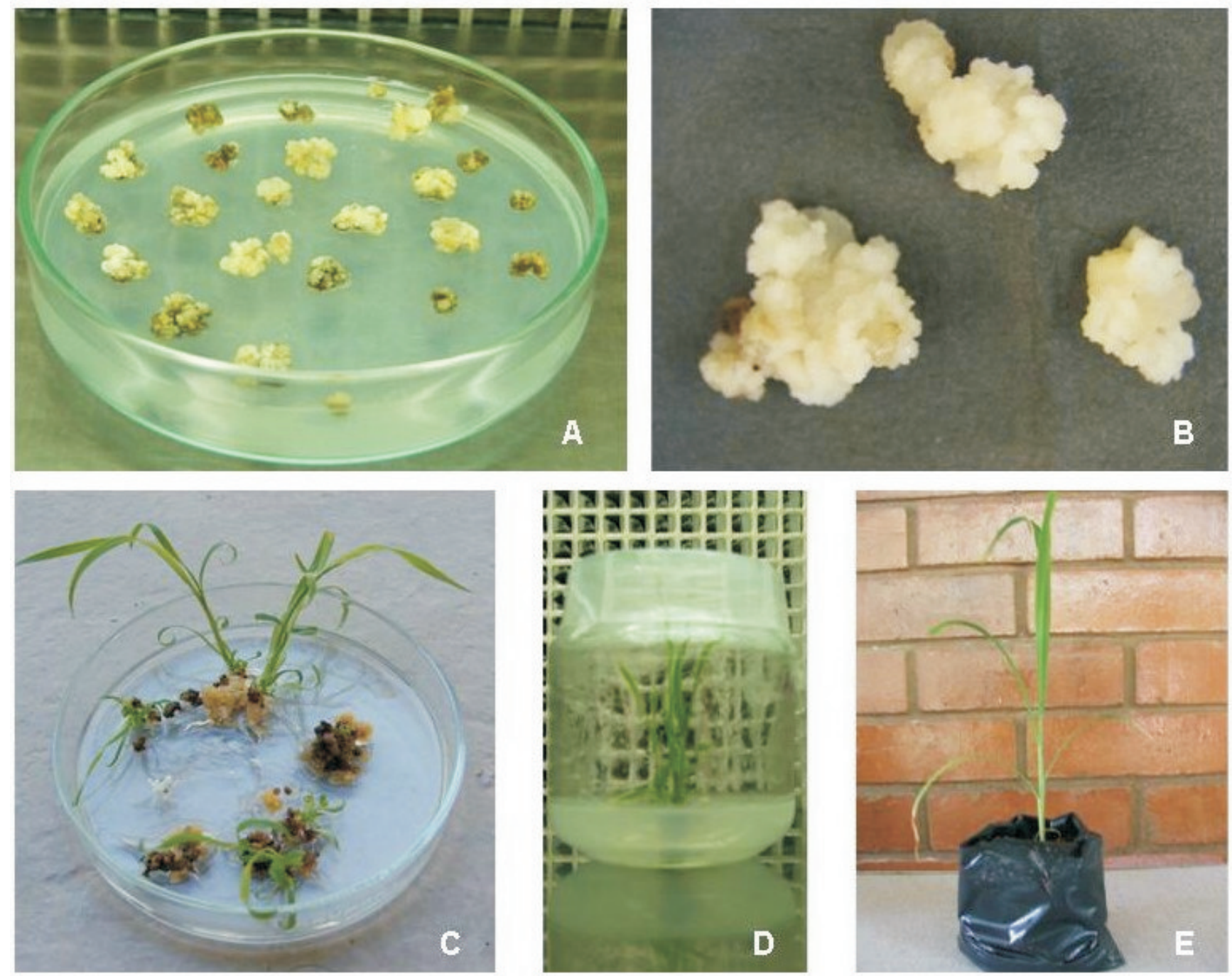

Figura 2. Regeneração de plantas por embriogênese somática, em híbrido de capim-elefante e milheto $(P$. purpureum $\mathrm{x}$ P. glaucum). A e B, calos embriogênicos com seis semanas de cultivo em $1 \mathrm{mg} \mathrm{L}^{-1}$ de 2,4-D. C, brotos híbridos, após seis semanas de cultivo em meio MS sem reguladores de crescimento. D, brotos híbridos com raízes em meio MS sem reguladores de crescimento (quatro semanas). E, planta aclimatada após quatro semanas. Fotos de Marcelo de Oliveira Santos. 
mostrados na Figura 3. Para duas plantas obtidas por embriogênese somática, foi possível detectar a presença de células com quantidades de DNA equivalentes a 12x. Provavelmente, estas estimativas se referem a células na fase G2 da interfase, oriundas de células hexaploides, o que indica a possibilidade de ocorrência de duplicação cromossômica em algumas células (Figura $3 \mathrm{C}$ e D). Essas plantas podem ser classificadas como mixoploides (que contêm tanto células triploides quanto hexaploides). As demais plantas obtidas por embriogênese e analisadas por citometria de fluxo foram classificadas como triploides estáveis, sem a presença de células com instabilidade genômica.

Vários autores têm demonstrado a importância dos coeficientes de variação dos picos G1 para boas estimativas da quantidade de DNA, em trabalhos com citometria de fluxo. Marie \& Brown (1993) propuseram coeficientes de variação de 1 a $2 \%$, para resultados de
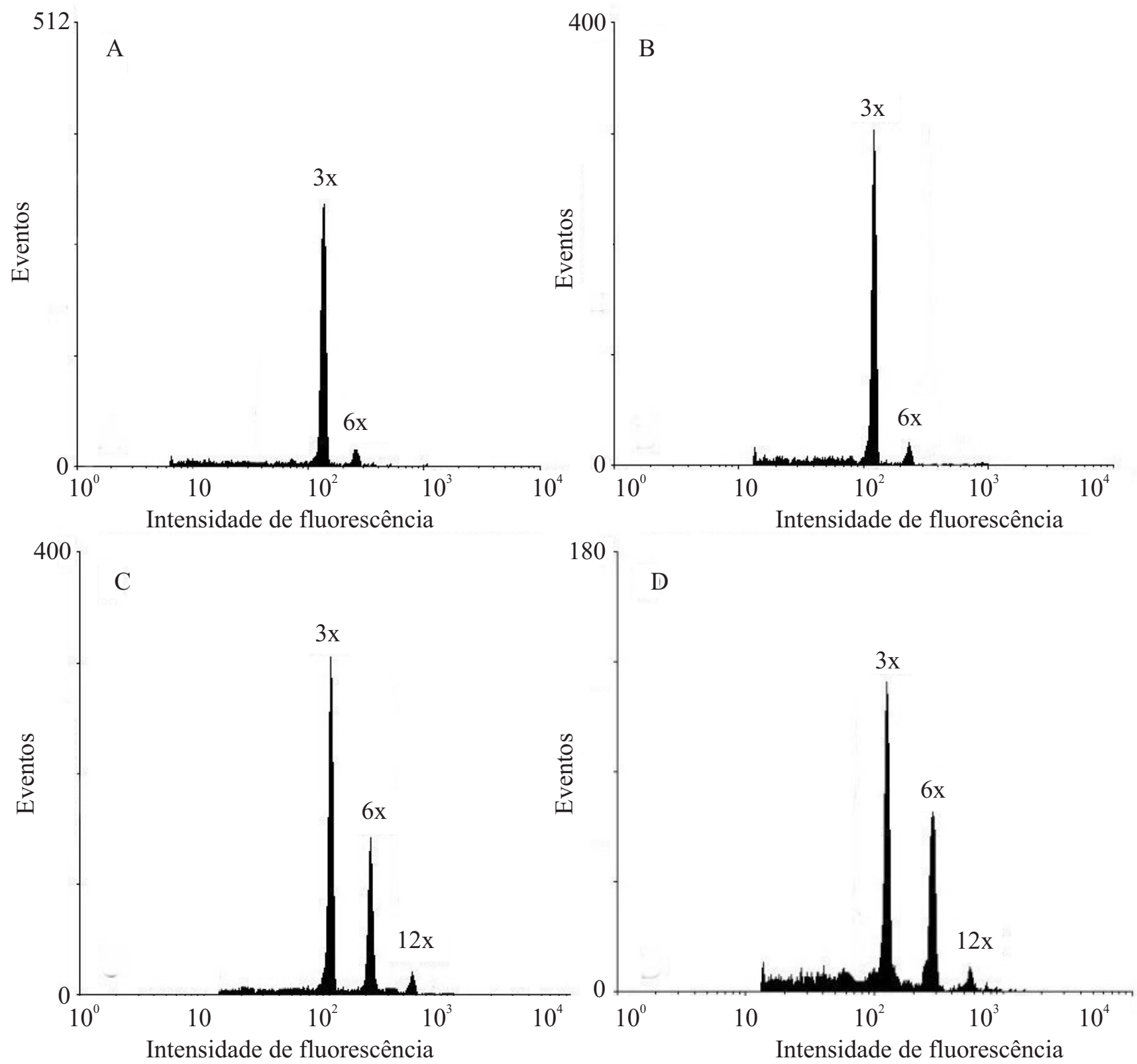

Figura 3. Histogramas de citometria de fluxo para quantificação de DNA. A, planta triploide controle. B, planta triploide, obtida por embriogênese somática, sem evidência de mudanças na quantidade de DNA, em relação à planta controle. $\mathrm{C}$ e D, plantas mixoploides, que possuem células hexaploides com complemento cromossômico duplicado. 
alta qualidade, e em torno de $3 \%$, para resultados de rotina. Galbraith et al. (2002) definiram o valor de $5 \%$ para os coeficientes de variação, como critério de aceitação das estimativas de quantidade de DNA. Outros autores que avaliaram a estabilidade genômica, em plantas mantidas in vitro, obtiveram coeficientes de variação entre 3,4 e 6,7\% (Alan et al., 2007; Loureiro et al., 2007). No presente trabalho, foram observados coeficientes de variação entre 1,32 e 3,11\%, com média de $1,87 \pm 0,37$, para as plantas controle, e $2,12 \pm 0,56$ para as plantas obtidas por embriogênese somática. Esses resultados são importantes, uma vez que permitem alta confiabilidade nas estimativas de quantidade de DNA obtidas, o que leva à conclusão sobre a não existência de instabilidade genômica nas plantas obtidas por embriogênese somática.

Dolezel et al. (2007) ressaltam, ainda, a importância dos coeficientes de variação para a detecção de aneuploidias. De modo geral, são adotados valores para os coeficientes de variação que sejam a metade da contribuição média, de cada cromossomo, para a quantidade total de DNA da planta analisada. No presente estudo, como o híbrido triploide apresenta 21 cromossomos, cada cromossomo contribui em média com $4,76 \%$ para a quantidade de DNA. Assim, o uso de coeficientes de variação abaixo de $2,38 \%$ permite detectar a perda de um único cromossomo nas plantas analisadas. Em 78\% das amostras avaliadas, nas plantas oriundas de embriogênese somática, os coeficientes de variação estiveram abaixo desse valor, o que permite uma conclusão confiável quanto à inexistência de aneuploidias nessas plantas.

Paralelamente aos estudos realizados para a definição de um método seguro para a propagação in vitro de genótipos elite de híbridos entre capim-elefante e milheto, a Embrapa Gado de Leite tem trabalhado para a obtenção de materiais hexaploides por meio da duplicação cromossômica de híbridos triploides (Abreu et al., 2006; Barbosa et al., 2007). Como as estratégias adotadas para duplicação cromossômica geralmente utilizam protocolos de exposição de explantes in vitro a agentes antimitóticos (Gu et al., 2005; Yang et al., 2006; Zhang et al., 2007), a obtenção de protocolos de embriogênese somática, para híbridos triploides de capim-elefante e milheto, além de representar uma possibilidade de multiplicação de genótipos elite, representa uma alternativa para indução in vitro de duplicação cromossômica, que visa à obtenção de híbridos hexaploides férteis.

\section{Conclusões}

1. A utilização de $1 \mathrm{mg} \mathrm{L}^{-1}$ de 2,4-ácido diclorofenoxiacético (2,4-D), para indução de calos embriogênicos, e de $1 \mathrm{~g} \mathrm{~L}^{-1}$ de inositol, para conversão de embriões e regeneração de plantas, é um sistema eficiente para obtenção de plantas híbridas entre capim-elefante e milheto por embriogênese somática.

2. Este sistema não induz alterações genômicas ou cariotípicas nas plantas regeneradas.

\section{Agradecimentos}

À Fundação deAmparoà Pesquisa do Estado deMinas Gerais e ao Conselho Nacional de Desenvolvimento Científico e Tecnológico, pelo apoio financeiro.

\section{Referências}

ABREU, J.C.; DAVIDE, L.C.; PEREIRA, A.V.; BARBOSA, S. Mixoploidia em híbridos de capim-elefante x milheto tratados com agentes antimitóticos. Pesquisa Agropecuária Brasileira, v.41, p.1629-1635, 2006.

ALAN, A.; ZENG, H.; ASSANI, A.; SHI, W.L.; MCRAE, H.E.; MURCH, S.J.; SAXENA, P.K. Assesment of genetic stability of the germplasm lines of medicinal plant Scutellaria baicalensis Georgi (Huang-qin) in long-term, in vitro maintained cultures. Plant Cell Reports, v.26, p.1345-1355, 2007.

AROCKIASAMY, S.; SAHAYA, R.S.; IGNACIMUTHU, S.; MELCHIAS, G. Efficient protocols for in vitro regeneration of Pennisetum glaucum (L.) Br. Indian Journal of Experimental Biology, v.44, p.757-761, 2006.

BARBOSA, S.; DAVIDE, L.C.; PEREIRA, A.V.; ABREU, J.C. Duplicação cromossômica de híbridos triplóides de capim-elefante e milheto. Bragantia, v.66, p.365-372, 2007.

BOTTI,C.;VASIL,I.K.Plantregeneration by somatic embryogenesis from parts of cultured mature embryos of Pennisetum americanum (L.) K. Schum. Zeitschrift für Pflanzenphysiologie, v.111, p.319-325, 1983.

CASSELS, A.C.; CURRY, R.F. Oxidative stress and physiological, epigenetic and genetic variability in plant tissue culture: implications for micropropagators and genetic engineers. Plant Cell, Tissue and Organ Culture, v.64, p.145-157, 2001.

DOLEZEL, J.; BARTOS, J. Plant DNA flow cytometry and estimation of nuclear genome size. Annals of Botany, v.95, p.99-110, 2005.

DOLEZEL, J.; GREILHUBER, J.; SUDA, J. Flow cytometry with plants cells. J. Wiley-VCH, [Weinheim]: 2007. 454p.

ENDERMANN, M.; HRISTOFOROGLU, K.; STAUBER, T.; WIHELM, E. Assessment of age-related polyploidy in Quercus robur L. somatic embryos and regenerated plants using DNA flow cytometry. Biologia Plantarum, v.44, p.339-345, 2001. 
GALBRAITH, D.W.; LAMBERT, G.; MACAS, J.; DOLEZEL, J. Analysis of nuclear DNA content and ploidy in higher plants. In: ROBINSON, J.; AZMI, A.; TUTOIS, S. (Ed.). Current Protocols in Cytometry. New York: John Wiley, 2002. 365p.

GU, X.F.; YANG, A.F.; MENG, H.; ZHANG, J.R. In vitro induction of tetraploid plants from diploid Zizyphus jujuba Mill. cv. Zhanhua. Plant Cell Report, v.24, p.671-676, 2005.

HANNA, W.W. Melhoramento do capim-elefante. In: PASSOS, L.P.; CARVALHO, L.A.; MARTINS, C.E.; PEREIRA, A.V. (Ed.). Biologia e manejo do capim-elefante. Juiz de Fora, Embrapa Gado de Leite, 1999. p.17-28.

HAYDU, Z.; VASIL, I.K. Somatic embryogenesis and plant regeneration from leaf tissues and anthers of Pennisetum purpureum Schum. Theoretical and Applied Genetics, v.59, p.269-273, 1981.

JAIN, S.M. Tissue culture-derived variation in crop improvement. Euphytica, v.118, p.153-166, 2001.

KIM, Y. Somatic embryogenesis in Quercus acutissima. In: JAIN, S.; GUPTA, P.; NEWTON, R. (Ed.). Somatic embryogenesis in woody plants. Dordrecht: Kluwer, 2000. p.671-686.

LAMBÉ, P.; MUTAMBEL, H.S.N.; DELTOUR, R.; DINANT, M. Somatic embryogenesis in pearl millet (Pennisetum glaucum): strategies to reduce genotype limitation and to maintain long-term totipotency. Plant Cell, Tissue and Organ Culture, v.55, p.23-29, 1998.

LOUREIRO, J.; CAPELO, A.; BRITO, G.; RODRIGUEZ, E.; SILVA, S.; PINTO, G.; SANTOS, C. Micropropagation of Juniperus phoenicea from adult plant explants and analysis of ploidy stability using flow cytometry. Biologia Plantarum, v.51, p.7-14, 2007.

MARIE, D.; BROWN, S. A cytometric exercise in plant DNA histograms, with $2 \mathrm{C}$ values for 70 species. Biology of the Cell, v.78, p.41-51, 1993.

MARTEL, E.; PONCET, V.; LAMY, F.; SILJAK-YAKOVLEV, S.; LEJEUNE, B.; SARR, A. Chromosome evolution of Pennisetum species (Poaceae): implications of ITS phylogeny. Plant Systematics and Evolution, v.249, p.139-149, 2004.
MARTEL, E.; RICROCH, A.; SARR, A. Assessment of genome organization among diploid species $(2 n=2 x=14)$ belonging to primary and tertiary gene pools of pearl millet using fluorescent in situ hybridization with rDNA probes. Genome, v.39, p.680-687, 1996.

MURASHIGE, T.; SKOOG, F. A revised media for rapid growth and bioassays with tobacco tissue cultures. Physiologia Plantarum, v.15, p.473-497, 1962.

PEREIRA, A.V.; VALLE, C.B.; FERREIRA, R.P.; MILLES, J.W. Melhoramento de forrageiras tropicais. In: NASS, L.L.; VALOIS, A.C.C.; MELO, I.S.; VALADARES-INGLIS, M.C. Recursos Genéticos e Melhoramento de Plantas. Cuiabá: Fundação Mato Grosso, 2001. 1183p.

PINTO, G.; LOUREIRO, J.; LOPES, T.; SANTOS, C. Analysis of genetic stability of Eucalyptus globulus Labill. somatic embryos by flow cytometry. Theoretical and Applied Genetics, v.109, p.580-587, 2004.

PIUS, J.; GEORGE, L.; EAPEN, S.; RAO, P.S. Enhanced plant regeneration in pearl millet (Pennisetum americanum) by ethylene inhibitors and cefotaxime. Plant Cell, Tissue and Organ Culture, v.32, p.91-96, 1993.

SCHANK, S.C.; DIZ, D.A.; BATES, D.B.; THOMPSON, K.E. Genetic improvement of napiergrass and hybrids with pearl millet. Biomass and Bioenergy, v.5, p.35-40, 1993.

SOUZA SOBRINHO, F.; PEREIRA, A.V.; LEDO, F.I.S.; BOTREL, M.A.; OLIVEIRA, J.S.; XAVIER, D.F. Avaliação agronômica de híbridos interespecíficos entre capim-elefante e milheto. Pesquisa Agropecuária Brasileira, v.40, p.873-880, 2005.

YANG, X.M.; CAO, Z.Y.; AN, L.Z.; WANG, Y.M.; FANG, X.M. In vitro tetraploid induction via colchicine treatment from diploid somatic embryos in grapevine (Vitis vinifera L.). Euphytica, v.152, p.217-224, 2006.

ZHANG, J.; ZHANG, M.; DENG, X. Obtaining autotetraploids in vitro at a high frequency in Citrus sinensis. Plant Cell, Tissue and Organ Culture, v.89, p.211-216, 2007.

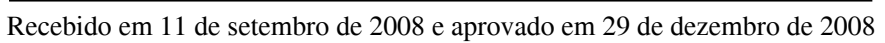

